\title{
Use of geographic information system as a tool for schistosomiasis surveillance in an endemic Municipality in Eastern Samar, The Philippines
}

\author{
Vicente Y. Belizario, Jr., ${ }^{1,2}$ John Paul Caesar R. delos Trinos, ${ }^{2,3}$ Nestor Lentejas, ${ }^{4}$ \\ Allen J. Alonte, ${ }^{2}$ Agnes N. Cuayzon, ${ }^{5}$ Marian E. Isiderio, ${ }^{6}$ Rodel Delgado, ${ }^{6}$ Marilou Tejero, ${ }^{7}$ \\ Victorio B. Molina ${ }^{1}$ \\ ${ }^{1}$ College of Public Health, University of the Philippines Manila, Manila, Philippines; ${ }^{2}$ Neglected Tropical \\ Diseases Study Group, National Institutes of Health, University of the Philippines Manila, Manila, \\ Philippines; ${ }^{3}$ Kirby Institute, University of New South Wales Sydney, Sydney, Australia; ${ }^{4}$ Plan International \\ Philippines, Makati, Philippines; ${ }^{5}$ Department of Health Centre for Health Development, Eastern Visayas, \\ Philippines; ${ }^{6}$ Provincial Health Office, Eastern Samar, Philippines; ${ }^{7}$ Municipal Health Office, Oras, \\ Eastern Samar, Philippines
}

\begin{abstract}
This study aimed to demonstrate the use of geographic information systems (GIS) in identifying factors contributing to schistosomiasis endemicity and identifying high-risk areas in a schistosomiasis-endemic municipality in the Philippines, which was devastated by Typhoon Haiyan in 2013. Data on schistosomiasis determinants, obtained through literature review, the Philippine Department of Health, and concerned local government units, were standardized and incorporated into a GIS map using ArcGIS. Data gathered included modifiable [agriculture, poverty, sanitation, presence of intermediate and reservoir hosts, disease prevalence and mass drug administration (MDA) coverage] and non-
\end{abstract}

Correspondence: Vicente Y. Belizario, Jr., College of Public Health, University of the Philippines Manila, 625 Pedro Gil St., Ermita, Manila, 1000 Metro Manila, the Philippines.

Tel.: +632.523.5929 - loc. 142. E-mail: vybelizario@up.edu.ph

Key words: Schistosomiasis; geographic information systems; surveillance; Eastern Samar; the Philippines; war on worms; nutrition; water; sanitation; hygiene.

Acknowledgements: the researchers would like to acknowledge the partner institutions, such as Plan International Philippines, DOH RO VIII, Eastern Samar provincial LGU, and Oras municipal LGU, as well as Ms. Lynnell Alexie D. Ong, for their valuable contributions which made this study possible. The researchers would also like to thank United States Agency for International Development and RTI International for providing research funds.

Received for publication: 15 November 2020.

Revision received: 2 March 2021.

Accepted for publication: 3 March 2021.

(C) Copyright: the Author(s), 2021

Licensee PAGEPress, Italy

Geospatial Health 2021; 16:957

doi:10.4081/gh.2021.957

This article is distributed under the terms of the Creative Commons Attribution Noncommercial License (CC BY-NC 4.0) which permits any noncommercial use, distribution, and reproduction in any medium, provided the original author(s) and source are credited. modifiable (geography and climate) determinants for schistosomiasis. Results showed that most barangays (villages) are characterized by favourable conditions for schistosomiasis transmission

which include being located in flood-prone areas, presence of vegetation, low sanitary toilet coverage, presence of snail intermediate host, high carabao (water buffalo) population density, previously reported $\geq 1 \%$ prevalence using Kato-Katz technique, and low MDA coverage. Similarly, barangays not known to be endemic for schistosomiasis but also characterized by the same favourable conditions for schistosomiasis as listed above and may therefore be considered as potentially endemic, even if not being high-risk areas. This study demonstrated the importance of GIS technology in characterizing schistosomiasis transmission. Maps generated through application of GIS technology are useful in guiding program policy and planning at the local level for an effective and sustainable schistosomiasis control and prevention.

\section{Introduction}

Schistosomiasis, caused by the blood fluke Schistosoma spp., is a debilitating and potentially fatal neglected tropical disease (NTD) affecting about 240 million people according to the World Health Organization (WHO, 2020). It persists in areas where access to adequate sanitation and hygiene is limited, and remains a public health concern in low- and middle-income countries such as the Philippines. Transmission occurs through skin penetration by infective cercariae released by the intermediate snail host Oncomelania hupensis quadrasi during contact with contaminated waters (WHO, 2020). It is associated with morbidities such as under-nutrition, impaired cognitive processes, decreased work productivity and chronic abdominal or pelvic pain (King et al., 2005). WHO aims to eliminate schistosomiasis by 2030 as a public health problem, defined as reducing prevalence of heavy intensity infections to $<1 \%$ (WHO, 2020).

In the Philippines, schistosomiasis, caused by S. japonicum, remains endemic and according to the Philippine Department of Health (DOH) 189 municipalities and 15 cities in 28 provinces are infected, with approximately 2.5 million people at risk for the infection (DOH, 2018). The local government units (LGUs) in collaboration with DOH, through the Schistosomiasis Control and Elimination Program, implements community-based mass drug administration (MDA) of praziquantel every January as a key 
strategy for schistosomiasis morbidity control (DOH, 2007; 2016). Other strategies include case-finding and management; promotion of veterinary public health; snail control and surveillance; and improvements in water and sanitation facilities in all endemic areas (DOH, 2018). Pockets of high endemicity, however, are still observed despite a decade of program implementation ( $\mathrm{DOH}$, 2018). Among these is the Eastern Samar Province, which remains endemic for schistosomiasis with a prevalence of $4.3 \%$ in schoolage children according to the regional office of the $\mathrm{DOH}(\mathrm{DOH}$ RO VIII, 2016). In November 2013, the strongest typhoon (Haiyan) to ever hit the Philippines, devastated the province and posed challenges in schistosomiasis control as it disrupted the local health service delivery and compromised access to safe water and sanitation (United Nations Children's Fund, 2015; Salazar et al., 2017). Inadequate water supply, limited access to sanitation facilities and poor hygiene practices are major contributing factors to the spread of schistosomiasis (Kouadio et al., 2012).

Surveillance is needed to assess the status of schistosomiasis and identify the needed interventions for effective infection control. The WHO recommends mapping of endemicity as part of surveillance to allow identification of high-risk areas for the infection, which allows implementation of targeted delivery of services, especially when resources are limited (WHO, 2020).

The utility of geographic information systems (GIS), a computer-based tool designed to integrate, analyse, and visualize spatial information (Higgs, 2004), in mapping schistosomiasis endemicity has been demonstrated in several studies. It has been effectively used in Anhui Province in China to identify high-risk areas and possible transmission of schistosomiasis in other areas (Hu et al., 2015). In the Philippines, GIS together with remote sensing was used to demonstrate how land use and topography affect spatial distribution of malaria and schistosomiasis in the province of Davao del Norte (Leonardo et al., 2005). In the same province, GIS was also used to determine the relationship of various schistosomiasis determinants which may contribute to transmission of the infection (Belizario et al., 2017). These studies exemplified very well how to visualize the factors contributing to schistosomiasis through GIS maps.

The War-on-Worms, the Nutrition, Water, Sanitation, and Hygiene Project led by the University of the Philippines in Manila in partnership with Plan International Philippines, investigated the status of schistosomiasis in Eastern Visayas (a major group of islands in the Philippines) after Typhoon Haiyan. As part of the project, this study aimed to demonstrate the use of GIS in identifying factors contributing to schistosomiasis endemicity and highrisk areas in an endemic and Haiyan-stricken municipality in Eastern Samar, one of the provinces in Visayas.

\section{Materials and methods}

\section{Study location}

Eastern Samar, a province in the Eastern Visayas region, is composed of 23 municipalities (Philippine Statistics Authority, 2015), ten of which are known to be endemic for schistosomiasis (DOH, 2009). Schistosomiasis prevalence in the province is $4.3 \%$ in school-age children (DOH RO VIII, 2016). Oras, a low income municipality, was selected as the study site due to its known endemicity for the infection with 25 out of 42 barangays (villages) known to be schistosomiasis-endemic (DOH RO VIII, 2016) (Figure 1). This selection was based on availability of data on factors contributing to schistosomiasis endemicity as well as active participation of and partnership with local stakeholders, such as the DOH and LGUs, could be counted on.

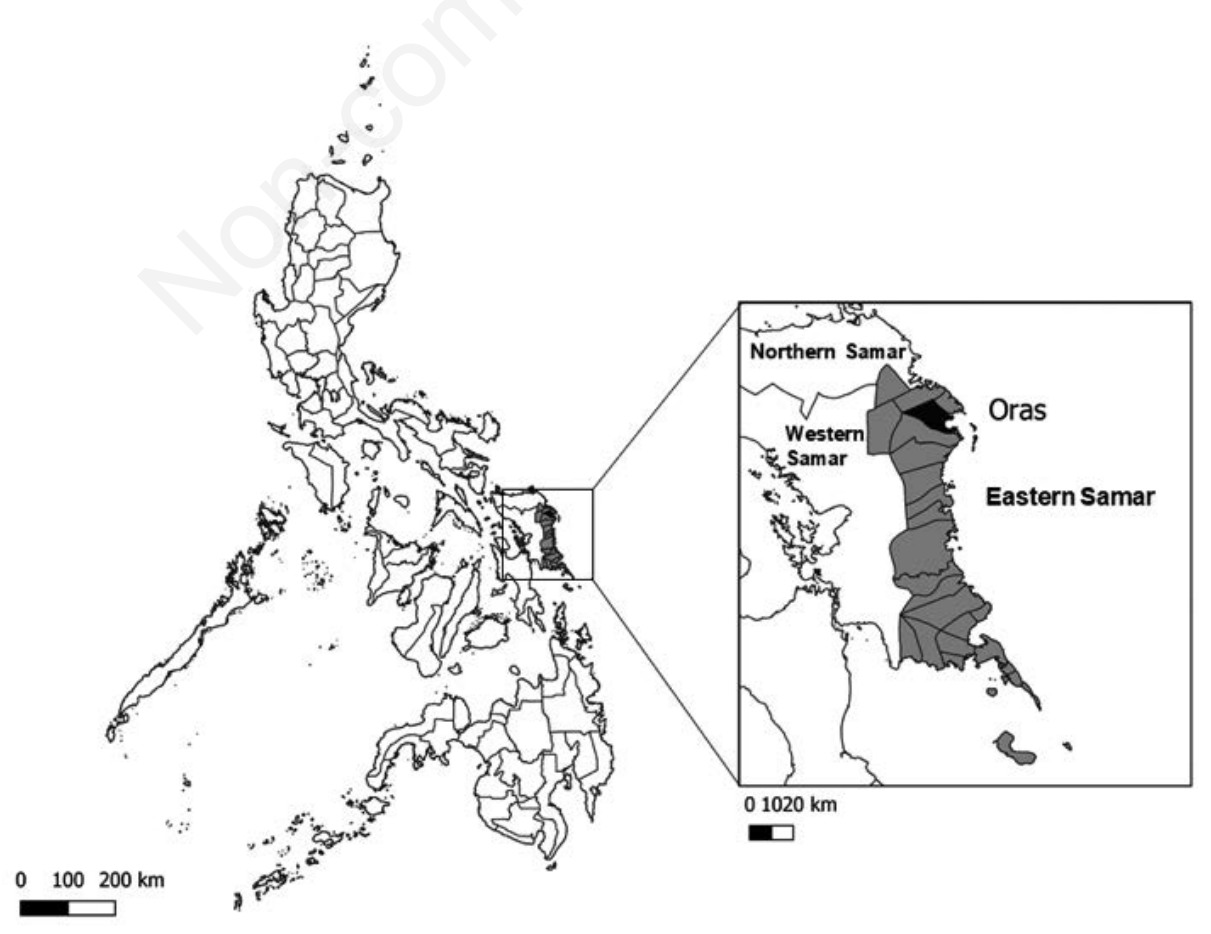

Figure 1. Map of the Philippines (left) and Eastern Samar Province (right) with the Oras Municipality. 


\section{Data collection and processing}

A literature review was conducted to identify the determinants of schistosomiasis endemicity such as geography and climate; agriculture; poverty; sanitation; presence of intermediate and reservoir hosts; and MDA coverage. Specific variables from each determinant were identified, and conditions favourable for the infection were also obtained through this literature review. Sources of the identified schistosomiasis variables were determined through review of records and consultations with key staff from the DOH Eastern Visayas-Centre for Health Development; the Provincial Health Office of Eastern Samar; and the Municipal Health Office of Oras, through a stakeholders' meeting. The latest quantitative data were obtained from the $\mathrm{DOH}$, concerned LGUs and other relevant local agencies (Table 1).

Data on the determinants and variables identified were entered in ArcGIS, v. 10.2.1 (ESRI Inc.; Redlands, CA, USA) to create map layers. The generated layers were integrated and used to determine high-risk areas for schistosomiasis.

Geographical and climate maps were constructed by adjusting the data to the national bounding box and re-projected to local coordinates. Raster resolution used was one $\mathrm{km}$. Data on types of irrigation and land use (e.g., types of crops planted) for the year 2015 were obtained from the provincial and municipal Planning Development Office.

Poverty incidence data, obtained from the Philippine Statistics Authority was compared with the national target of $<14 \%$ (NEDA, 2017). Barangays were classified according to sanitary toilet coverage: i) meeting the national target of $100 \%$ (DOH, 2010); ii) meeting the LGU target of $\geq 92 \%$ (Eastern Samar Provincial Health Office, 2016); or iii) $<92 \%$. Barangays were also classified according to the Rural Sanitation Graduation Framework as either: i)
Barangays with open defecation areas; ii) Grade 1 barangays, which have zero open defecation (ZOD) in the village; iii) Grade 2 barangays, which have sustainable sanitation (i.e. each household has its own toilet); and iv) Grade 3 barangays, which have complete solid waste and waste water management, including drainage (DOH, 2010)

The locations of snail sites were geo-tagged using a global positioning system (GPS) and marked on the generated GIS map. Data were limited to areas where the $\mathrm{DOH}$ routinely conducts malacological surveys. O. hupensis quadrasi snail colonies with available data on prevalence of schistosomiasis in snails were classified as either having a prevalence of $<8 \%$ or one $\geq 8 \%$. Barangays were also classified as having a carabao (water buffalo) population density of either $0-15$ or $16-30$ carabaos per 100 population. These thresholds were based on expert opinion.

Prevalence of schistosomiasis per barangay was compared with the national target of $<1 \%$ (DOH, 2007). Selected barangays were also classified based on seroprevalence. Based on prevalence, the barangays were classified as high-risk ( $\geq 50 \%)$; moderate-risk (10-50\%); or low-risk $(<10 \%)$ communities (WHO, 2006). seroprevalence of $\geq 10 \%$ were considered favourable for schistosomiasis transmission based on expert opinion. The MDA coverage for schistosomiasis per barangay in 2016 was obtained from Oras Rural Health Unit (2016) and compared with the target coverage of $<75 \%$ (WHO, 2006).

A workshop involving representatives from $\mathrm{DOH}$ and involved LGU offices was held in September 2017 to present data on schistosomiasis determinants. A prototype GIS map was developed thereafter. Standardized data, following the specifications of ArcGIS 10.2.1, were incorporated in the GIS map by digitizing or tracing the location, path, or boundary of geographic features. Each GIS map layer corresponded to a unique schistosomiasis

Table 1. Determinants, variables, data sources, and conditions favourable for schistosomiasis transmission integrated in GIS map for Eastern Samar, the Philippines.

\begin{tabular}{|c|c|c|c|c|}
\hline Determinant & Variable & $\begin{array}{l}\text { Data source } \\
\text { (year of collection) }\end{array}$ & Condition promoting transmission & Reference \\
\hline Geography and climate & $\begin{array}{l}\text { Topography } \\
\text { Flood-prone areas } \\
\text { Temperature }\end{array}$ & $\begin{array}{l}\text { Eastern Samar PPD0 (2015) } \\
\text { Oras MPD0 (2015) } \\
\text { World Clim (2000) }\end{array}$ & $\begin{array}{l}\text { Presence of bodies } \\
\text { of freshwater } \\
\text { Presence of flood-prone areas } \\
\text { Temperatures ranging from } 15.4-30^{\circ} \mathrm{C}\end{array}$ & $\begin{array}{l}\text { Grimes et al., } 2015 \\
\text { Katanha \& Masocha, } 2014 \\
\text { Yang et al., 2007; } \\
\text { Zhou et al., } 2009\end{array}$ \\
\hline Agriculture & $\begin{array}{l}\text { Irrigation } \\
\text { Land use (e.g. types of crops planted) }\end{array}$ & $\begin{array}{l}\text { Eastern Samar PPDO (2015) } \\
\text { Oras MPDO (2015) }\end{array}$ & $\begin{array}{l}\text { Presence of irrigation canals and dams } \\
\text { Lands used for vegetation }\end{array}$ & $\begin{array}{l}\text { McManus et al., } 2010 \\
\text { Zhang et al., } 2003\end{array}$ \\
\hline Poverty & Poverty incidence & PSA (2015) & Poverty incidence of $>14 \%$ & NEDA, 2017 \\
\hline Sanitation & $\begin{array}{l}\text { Sanitary toilet coverage } \\
\text { ZOD status }\end{array}$ & $\begin{array}{l}\text { Oras MHO (2016) } \\
\text { Eastern Samar PHO (2016) }\end{array}$ & $\begin{array}{l}\text { Below the LGU target of 92\% } \\
\text { Non-ZOD }\end{array}$ & $\begin{array}{l}\text { Philippine DOH, } 2010 \\
\text { Philippine DOH, } 2010\end{array}$ \\
\hline Presence of intermediate hosts & $\begin{array}{l}\text { Snail colonies } \\
\text { Schistosomiasis prevalence in snails }\end{array}$ & Philippine DOH RO VIII (2015) & $\begin{array}{l}\text { Presence of snail colonies } \\
\text { Prevalence of infection } \\
\text { in snails of } \geq 8 \%\end{array}$ & $\begin{array}{l}\text { Philippine DOH, } 2007 \\
\text { Expert opinion }\end{array}$ \\
\hline
\end{tabular}

\begin{tabular}{lllll} 
Presence of animal reservoir hosts & Carabao population density & Eastern Samar PAGRO (2016) & Presence of carabao as animal reservoir host Gray et al., 2009 \\
\hline Disease prevalence & $\begin{array}{l}\text { Schistosomiasis prevalence using } \\
\text { Kato-Katz technique }\end{array}$ & Philippine DOH RO VIII (2016) & Schistosomiasis prevalence of $\geq 1 \%$ & WH0, 2012 \\
& $\begin{array}{l}\text { Schistosomiasis seroprevalence } \\
\text { using ELISA antibody }\end{array}$ & Belizario et al. (2018) & Schistosomiasis seroprevalence of $\geq 10 \%$ & Expert opinion \\
MDA coverage & MDA coverage of praziquantel & Philippine DOH RO VIII (2016) & $\begin{array}{l}<75 \% \text { MDA } \\
\text { coverage rates of praziquantel }\end{array}$ & WH0, 2012
\end{tabular}

DOH, Department of Health; DOH RO VIII, Department of Health Regional Office VIII; ELISA, enzyme-linked immunosorbent assay; MDA, mass drug administration; MHO, Municipal Health Office; MPDO, Municipal Planning and Development Office; NEDA, National Economic and Development Authority; PAGRO, Provincial Agricultural Office; PHO, Provincial Health Office; PPDO, Provincial Planning and Development Office; PSA, Philippine Statistics Authority; WHO, World Health Organization; ZOD, zero open defecation. 
determinant and were overlaid in the computer to highlight patterns and trends. Colours and symbols were used to distinguish different attributes. Follow-up workshops were conducted in November 2017 to discuss the draft version of the GIS map and in January 2018 to discuss the pre-final version.

\section{Results}

\section{Geography, climate, and agriculture}

Oras has forested areas in the western part of the municipality and wide plains in the central lowland areas. All the 25 barangays known to be schistosomiasis-endemic are adjacent to each other in the lowland areas. These include Batang, Cadia-an, Cagpile, Cagtu-og and Rizal in the North; Balingasag, Gamot and Naga in the West; Agsam, Balocawe, Binalayan, Burak, Paypayon and Tawagan in the East; and Bagacay, Bantayan, Bato, Dalid, Dao, Factoria, Japay, Kalaw, Mabuhay, Saugan and Trinidad in the South. Barangays not known to be endemic for the infection are mostly near the coastal areas and not adjacent to major bodies of freshwater. Flood-prone areas are concentrated in the southern and south-eastern lowland areas, and the barangays known to be endemic are located around major rivers of these plains.
Temperatures in the study are vary within the $15.4-29.0^{\circ} \mathrm{C}$ range, with known schistosomiasis-endemic barangays having relatively high temperatures, except those in the southern area. The mountainous part of Oras consists of shrub lands or forests, while the lowlands are mostly used as rain-fed rice fields, which are also seen near flood-prone areas (Figure 2).

\section{Poverty and sanitation}

Oras had a poverty incidence of 54\% in 2015 and overall sanitary toilet coverage of $72 \%$ in 2016 . Twenty-eight out of the 42 barangays had $<92 \%$ sanitary toilet coverage. Those in the East (Malingon, Pangudton and Riverside) as well as in the South (Dalid and Mabuhay) have $<100 \%$ sanitary toilet coverage although they were declared G1 ZOD barangays (Figure 3).

\section{Intermediate snail hosts and animal reservoir hosts}

Information on the presence of the non-human hosts is shown in Figure 3. Six out of the ten identified snail colonies in Oras were in flood-prone areas where sanitary toilet coverage was below the provincial target. Four snail colonies were in barangays not known to be endemic (Buntay, Cagdine and Iwayan) in the North and San Roque in the East. Prevalence of schistosomiasis in snails were $<8 \%$ in Cagdine and $\geq 8 \%$ in Agsam, Buntay, Cadia-an, Iwayan, Paypayon and San Roque. High carabao population densities were observed in known endemic barangays, namely Rizal in the North;

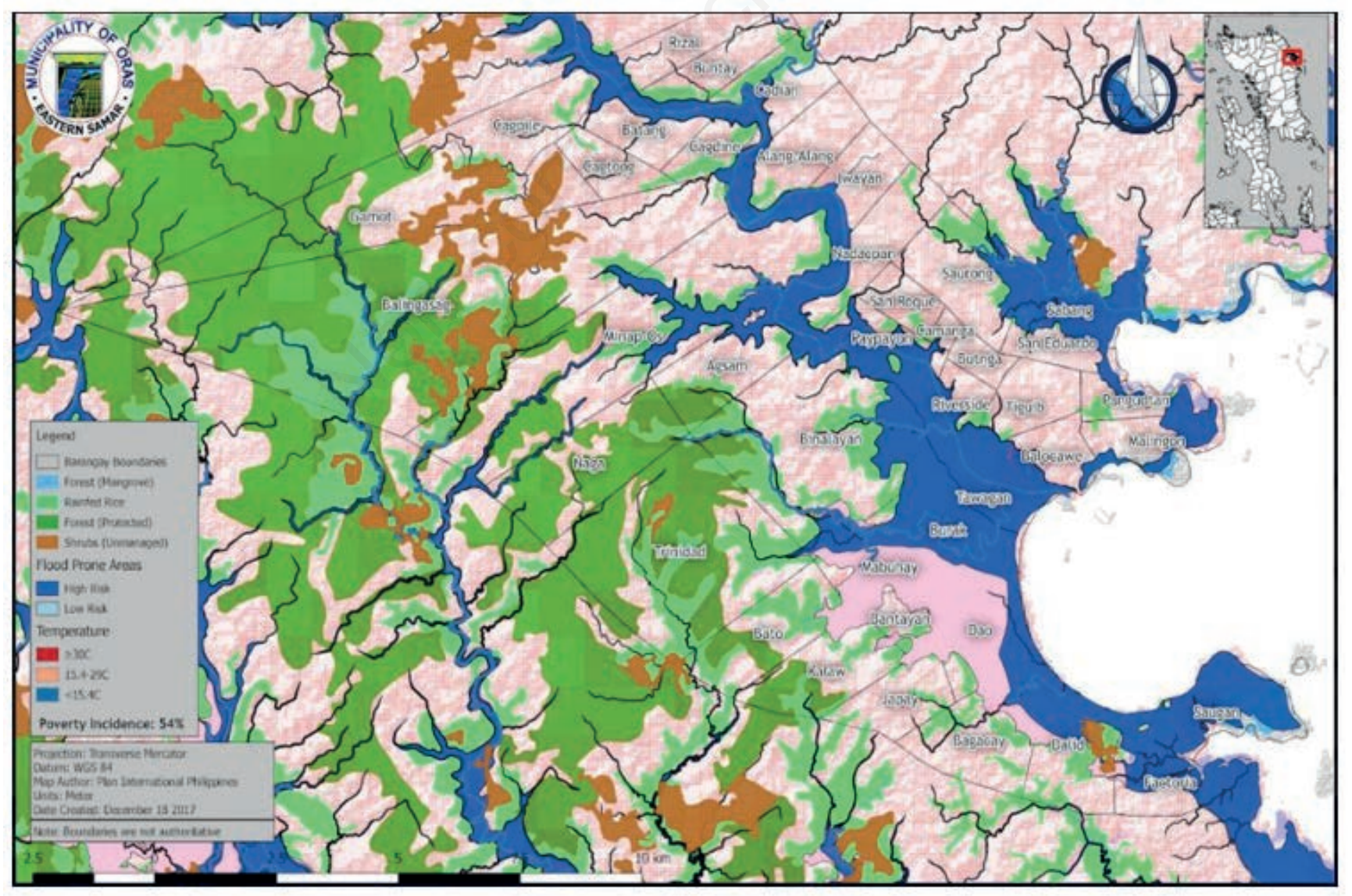

Figure 2. Topography, flood-prone areas, temperature and poverty incidence in Oras, Eastern Samar. 
Binalayan and Trinidad in the East; Naga in the West; and Bato and Kalaw in the South (Figure 3).

\section{Schistosomiasis prevalence and mass drug administra- tion coverage}

Schistosomiasis prevalence of $\geq 1 \%$ was found in 11 barangays in the North (Alang-alang, Batang, Cadia-an, Cagtu-og and Iwayan), in the East only Agsam, in the West only Cagpile, and in the South Bantayan, Dalid, Dao and Mabuhay. Two of these barangays, Alang-alang and Iwayan, were not known to be endemic for the infection. Data on seroprevalence were only available in the barangays of Binalayan, Mabuhay, Saugan and Tiguib. Moderate seroprevalence (10-49\%) was observed in Tiguib, whereas high seroprevalence $(\geq 50 \%)$ was reported in the three other barangays. High prevalence and seroprevalence were observed in Mabuhay, while high seroprevalence but $0 \%$ prevalence (using stool examination by Kato-Katz) were recorded in Saugan. The reported MDA coverage of praziquantel in all barangays was $<75 \%$ (Figure 4 ). The Municipal Health Office had no available praziquantel for MDA of the barangays Butinga and Sta. Monica.

\section{Schistosomiasis determinants and conditions considered}

Table 2 summarizes the presence of favourable conditions for schistosomiasis transmission in Oras, Eastern Samar. Favourable conditions include location in flood-prone areas, presence of vegetation, $<92 \%$ sanitary toilet coverage, presence of snail colonies, carabao population density of $16-30$ per 100 population, previously reported $\geq 1 \%$ prevalence of human schistosomiasis by stool examination, and $<75 \%$ MDA coverage. Twenty-six out of 42 barangays in Oras are in flood-prone areas and have vegetations such as rice fields and shrublands. Twenty-eight barangays did not meet the provincial target for sanitary toilet coverage, 19 of which were known to be endemic for schistosomiasis. Ten snail colonies were reported, six of which were in known endemic barangays and four in barangays not known to be endemic. Higher carabao density was observed in the known endemic barangays compared to those where endemicity was not known. All barangays with $\geq 1 \%$ human prevalence were located in flood-prone areas. No barangays have reached the MDA coverage target. In those considered to be non-endemic, such as Buntay, Iwayan and San Roque, were observed to have five out of seven identified conditions known to be favourable for schistosomiasis transmission.

\section{Discussion}

Topography, flood-prone areas, temperature, human activities (e.g., agriculture), poverty, sanitation, spatial distribution of intermediate and reservoir hosts, existing infection prevalence and

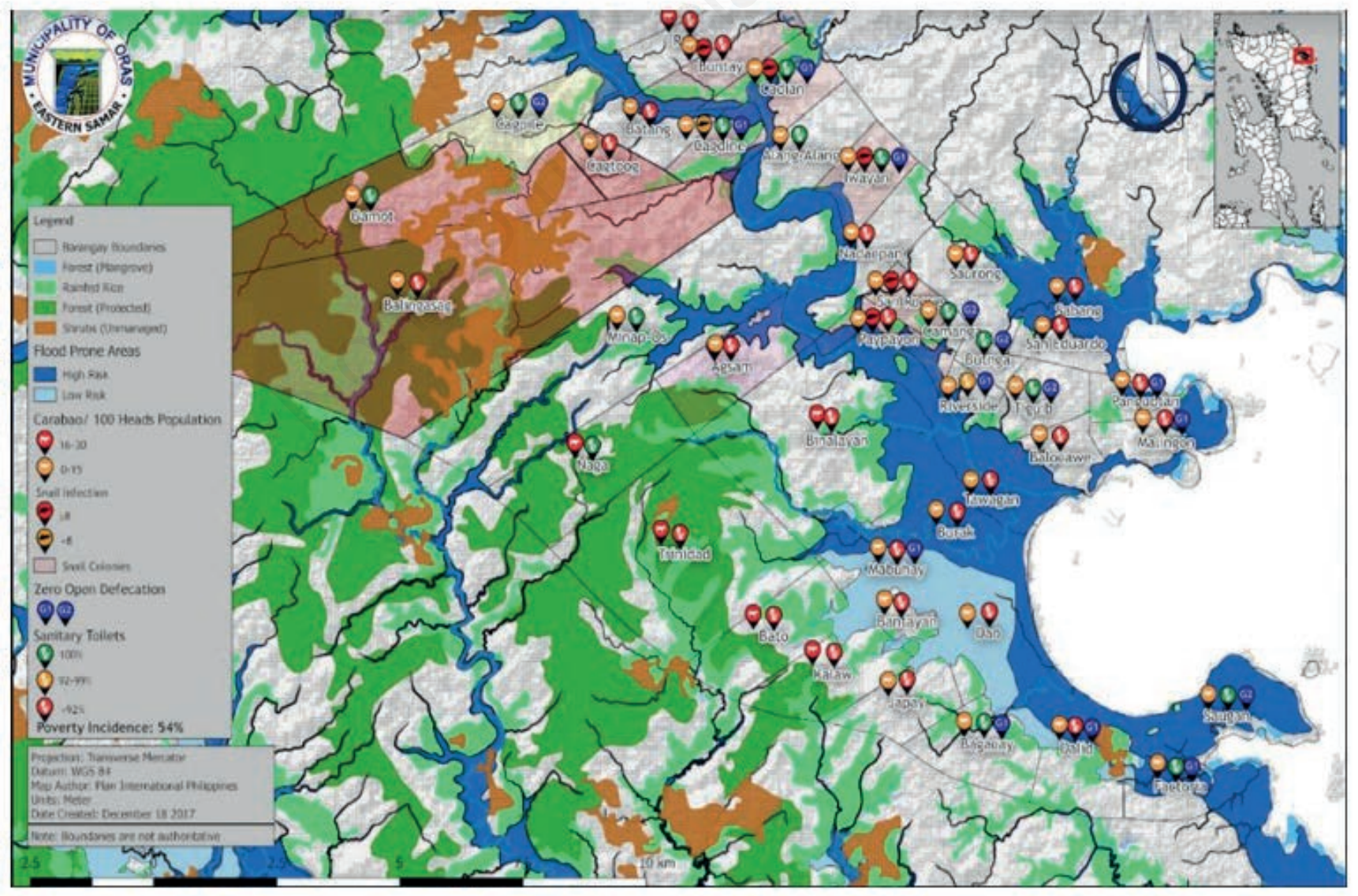

Figure 3. Carabao population density, snail prevalence, distribution of snail colonies and sanitation data in Oras, Eastern Samar overlaid with topography, flood-prone areas and poverty incidence. 
MDA coverage affect schistosomiasis transmission (Chen et al., 2015; Peng et al., 2010; Zhou et al., 2009). This study showed that flood-prone areas, presence of vegetations, low sanitary toilet coverage, presence of intermediate and reservoir hosts and low MDA coverage are conditions that should help identifying high-risk areas for schistosomiasis. Most of these determinants may be classified as modifiable, i.e. those where interventions are available to address them. However, the list includes also non-modifiable ones where interventions could only mitigate the effects.

The modifiable determinants in this study included presence of vegetation, sanitary toilet coverage and distribution of intermediate and reservoir hosts, prevalence of schistosomiasis, MDA coverage and poverty.

Vegetation, such as shrubs and rice crops, were found to be present in 8 out of 11 barangays with high prevalence of schistosomiasis, but they were also found in most other barangays. Vegetations commonly surrounds water bodies and are important in creating a conducive environment for breeding of the intermediate snail host of S. japonicum (Gordon et al., 2019). Weeding and thorough ploughing of rice fields or the change of land use from rice production to other crops are some of the practices proven to eliminate snail habitats (Gordon et al., 2019).

Twenty-eight barangays have low sanitary toilet coverage, 19 of which are known to be endemic. Low sanitary toilet coverage may encourage practice of open defaecation which contributes to ongoing transmission of schistosomiasis. Improving access to safe water and sanitation through health education and construction of sanitary toilets may help control the infection (Grimes et al., 2015).

Only ten snail colonies were identified by DOH; six in known endemic barangays and four in non-endemic barangays. Most of the identified snail colonies in Oras were in flood-prone areas. The $O$. hupensis quadrasi snail is amphibious but prefers an aquatic environment, such as wet soil surfaces, swamps, rice fields, ponds and the banks of rivers and streams. Preference of snails to aquatic environment makes chemical snail control difficult due to the risk of contaminating water and/or food sources (Gordon et al., 2019). Environmental modification through concrete-lining of canals, reclamation of swamps and clearing of vegetation have proved to reduce snail habitats in China and Japan (WHO, 2017).

Higher carabao population densities were observed in known endemic barangays. Bovines, such as carabaos, are considered as major reservoir hosts of $S$. japonicum. This is because infected bovines excrete up to $60 \mathrm{~kg}$ of stool daily into water bodies, such as lakes and rivers, where the animals frequently immerse or graze (Gray et al., 2009). Also, humans frequent these water sources, which highlight the importance of engaging the veterinary public health sector in providing technical assistance on animal surveillance and developing control strategies for the reservoir hosts (WHO, 2012). Deworming of bovines or replacement with tractors have been shown to be effective strategies in controlling schistosomiasis transmission (Gray et al., 2009).

Reported schistosomiasis prevalence of $\geq 1 \%$ were found in 11 barangays, two of which were considered non-endemic before this

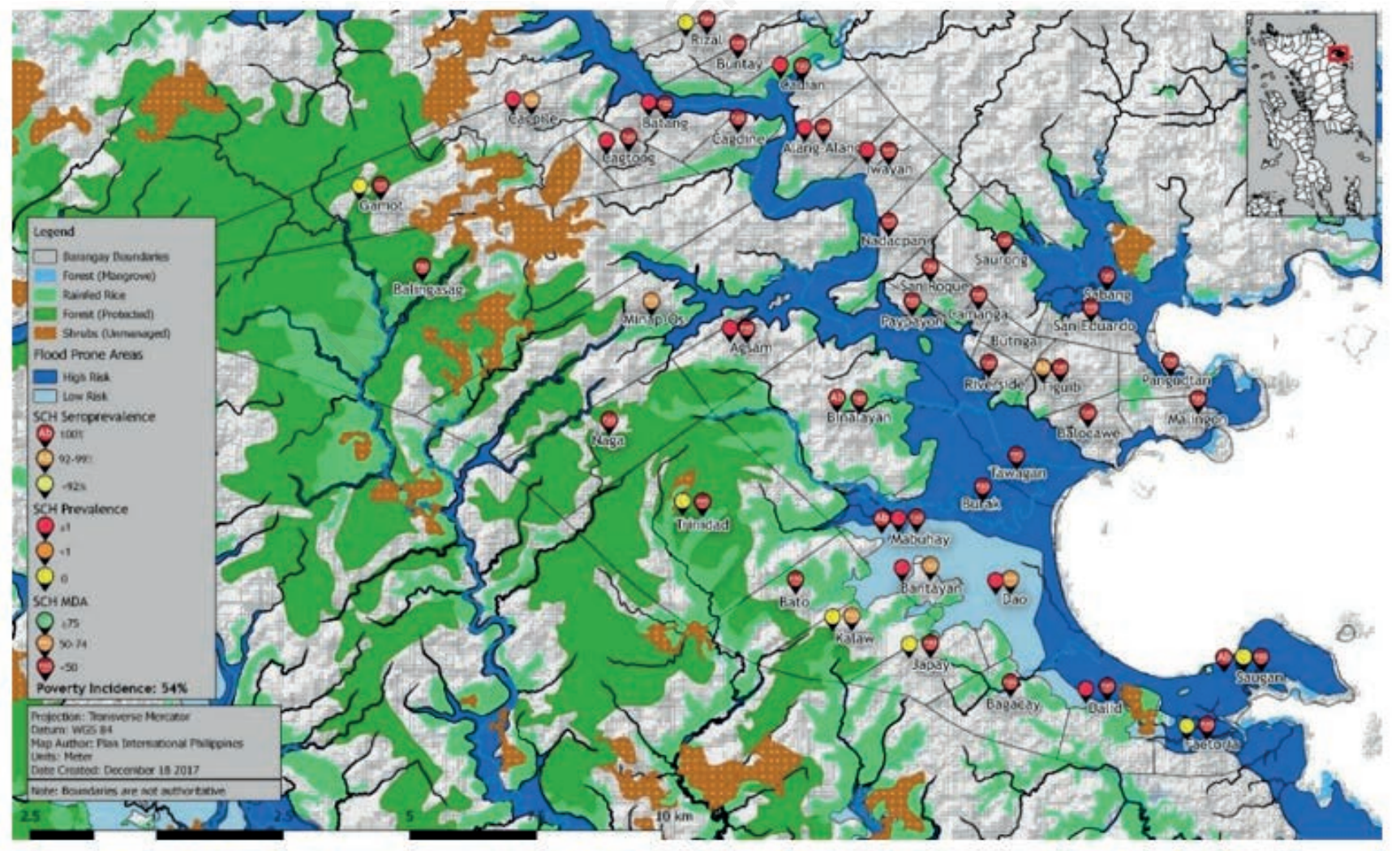

Figure 4. Schistosomiasis seroprevalence and prevalence and mass drug administration coverage of praziquantel in Oras, Eastern Samar overlaid with topography, flood-prone areas and poverty incidence. 
Table 2. Favourable conditions for schistosomiasis transmission in Oras, Eastern Samar, the Philippines.

\begin{tabular}{|c|c|c|c|c|c|c|c|}
\hline \multirow[b]{2}{*}{ Barangays } & \multicolumn{7}{|c|}{ Favourable conditions } \\
\hline & $\begin{array}{c}\text { Flood-prone } \\
\text { areas }\end{array}$ & $\begin{array}{c}\text { Presence of } \\
\text { vegetation }\end{array}$ & $\begin{array}{c}\text { Sanitary toilet } \\
\text { coverage } \\
<92 \%\end{array}$ & $\begin{array}{c}\text { Presence of } \\
\text { snail colonies }\end{array}$ & \begin{tabular}{|c|} 
Carabao \\
density of $16-$ \\
30 per 100 \\
population
\end{tabular} & \begin{tabular}{|c|}
$\begin{array}{c}\text { Prevalence of } \\
\geq 1 \% \text { using } \\
\text { Kato-Katz } \\
\text { technique }\end{array}$ \\
\end{tabular} & $\begin{array}{c}<75 \% \text { MDA } \\
\text { coverage of } \\
\text { praziquantel }\end{array}$ \\
\hline \multicolumn{8}{|c|}{ Known endemic barangays } \\
\hline \multicolumn{8}{|l|}{ Agsam } \\
\hline Bagacay & & & & & & $\mathrm{n} / \mathrm{a}$ & \\
\hline Balingasag & & & & & & $\mathrm{n} / \mathrm{a}$ & \\
\hline Balocawe & & & & & & $\mathrm{n} / \mathrm{a}$ & \\
\hline \multicolumn{8}{|l|}{ Bantayan } \\
\hline \multicolumn{8}{|l|}{ Batang } \\
\hline Bato & & & & & & $\mathrm{n} / \mathrm{a}$ & \\
\hline Binalayan & & & & & & $\mathrm{n} / \mathrm{a}$ & \\
\hline Burak & & & & & & $\mathrm{n} / \mathrm{a}$ & \\
\hline \multicolumn{8}{|l|}{ Cadia-an } \\
\hline \multicolumn{8}{|l|}{ Cagpile } \\
\hline \multicolumn{8}{|l|}{ Cagtu-og } \\
\hline \multicolumn{8}{|l|}{ Dalid } \\
\hline \multicolumn{8}{|l|}{ Dao } \\
\hline \multicolumn{8}{|l|}{ Factoria } \\
\hline \multicolumn{8}{|l|}{ Gamot } \\
\hline \multicolumn{8}{|l|}{ Japay } \\
\hline \multicolumn{8}{|l|}{ Kalaw } \\
\hline \multicolumn{8}{|l|}{ Mabuhay } \\
\hline Naga & & & & & & $\mathrm{n} / \mathrm{a}$ & \\
\hline Paypayon & & & & & & $\mathrm{n} / \mathrm{a}$ & \\
\hline \multicolumn{8}{|l|}{ Rizal } \\
\hline \multicolumn{8}{|l|}{ Saugan } \\
\hline Tawagan & & & & & & $\mathrm{n} / \mathrm{a}$ & \\
\hline \multicolumn{8}{|l|}{ Trinidad } \\
\hline \multicolumn{8}{|c|}{ Not known endemic barangays } \\
\hline \multicolumn{8}{|l|}{ Alang-alang } \\
\hline Buntay* & & & & & & $\mathrm{n} / \mathrm{a}$ & \\
\hline Butinga & & 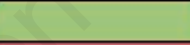 & & & $\mathrm{n} / \mathrm{a}$ & $\mathrm{n} / \mathrm{a}$ & $\mathrm{n} / \mathrm{a}$ \\
\hline Cagdine & & & & & & $\mathrm{n} / \mathrm{a}$ & \\
\hline Camanga & & & & & & $\mathrm{n} / \mathrm{a}$ & \\
\hline \multicolumn{8}{|l|}{ Iwayan* } \\
\hline Malingon & & & & & & $\mathrm{n} / \mathrm{a}$ & \\
\hline Minap-os & & & & & & $\mathrm{n} / \mathrm{a}$ & \\
\hline Nadacpan & & & & & & $\mathrm{n} / \mathrm{a}$ & \\
\hline Pangudtan & & & & & & $\mathrm{n} / \mathrm{a}$ & \\
\hline Riverside & & & & & & $\mathrm{n} / \mathrm{a}$ & \\
\hline Sabang & & & & & & $\mathrm{n} / \mathrm{a}$ & \\
\hline San Eduardo & & & & & & $\mathrm{n} / \mathrm{a}$ & \\
\hline San Roque* & & & & & & $\mathrm{n} / \mathrm{a}$ & \\
\hline Sta. Monica & $\mathrm{n} / \mathrm{a}$ & $\mathrm{n} / \mathrm{a}$ & & & $\mathrm{n} / \mathrm{a}$ & $\mathrm{n} / \mathrm{a}$ & $\mathrm{n} / \mathrm{a}$ \\
\hline Saurong & & & & & & $\mathrm{n} / \mathrm{a}$ & \\
\hline Tiguib & & & & & & $\mathrm{n} / \mathrm{a}$ & \\
\hline $\begin{array}{l}\square \text { Presence } \\
\square \text { Absence } \\
\text { n/a, no availa } \\
\text { *Barangays } n\end{array}$ & $\begin{array}{l}\text { favourable co } \\
\text { favourable co } \\
\text { data. } \\
\text { known to be e }\end{array}$ & $\begin{array}{l}\text { lition for schi } \\
\text { lition for schi }\end{array}$ & $\begin{array}{l}\text { stosomiasis } \\
\text { stosomiasis }\end{array}$ & & schist & nsm1 & \\
\hline
\end{tabular}


study, something which shows that surveillance should not only be limited to the known endemic barangays. The use of more accurate diagnostic tools, e.g., detection of the circulating cathodic schistosome antigen in the definitive host (van Dam et al., 2015) and detection of the infection in the snail by means of loop-mediated isothermal amplification (Qin et al., 2018), would be more helpful in mapping out possible sources of infection especially in lowtransmission areas. Serological techniques may also be considered for surveillance particularly in low-endemicity area where determining exposure, which serology detects, is more important than differentiating past from active infection. Limitations, such as cross-reactivity and false positive reactions, must however be considered in the interpretation of the results (WHO, 2017). As observed in this study, prevalence of $<1 \%$ using the Kato-Katz technique was reported in Saugan, while $>50 \%$ seroprevalence was reported.

Community-based MDA of praziquantel in known endemic areas is recommended by WHO as a strategy to control morbidity and reduce transmission (WHO, 2006). In Oras, generally low MDA coverage was observed in both known and not known endemic barangays. House-to-house delivery of the drug, improving health awareness through health education and ensuring sufficiency of drug supply are among the strategies which can help improve MDA coverage (Deardorff et al., 2018).

Oras, a known endemic municipality, had a high poverty incidence $(54 \%)$ (NEDA, 2017). Poverty often restricts community access to clean water sources and basic sanitation facilities and forces people to engage in occupations which exposes them to infection, such as fishing and farming (King, 2010). The infection leads to decreased productivity in the community creating a vicious cycle of schistosomiasis and poverty. Uplifting the economic status of the community through poverty reduction strategies may help in controlling schistosomiasis and ending the cycle (Karunamoorthi et al., 2018).

Flood-prone areas, topography and temperature were considered non-modifiable determinants in this study. Although nonmodifiable, appropriate preventive measures can be applied to mitigate the infection risk. Eighteen out of 25 known endemic barangays were in flood-prone areas. Flooding brought by typhoons may lead to snail dispersal increasing the area of potential snail habitats. Studies in China found that spread of $O$. hupensis quadrasi snails to farmlands could still be observed ten years after a flood (Zhou et al., 2001). An outbreak may also occur since flooding may expose more people to contaminated water as the cercariae are reported to survive for up to 48 hours after release from the intermediate snail host (Kerr, 2004). Health education focusing on effective protection against schistosomiasis during flooding and strengthening surveillance after floods with respect to infection outbreaks and new snail habitats are strategies which may be helpful in reducing the infection risk. Collaboration among the regional health and agricultural offices, disaster risk reduction management units, LGUs, private sector and other stakeholders should be strengthened, with sharing of resources encouraged $(\mathrm{Wu}$ et al., 2008).

Land elevation may affect transmission, as low-land areas near water bodies may become potential animal habitats (Gordon et al., 2019). We showed that most of the known endemic barangays were in low-land areas, which are adjacent to each other, similar to the findings in Davao del Norte (Belizario et al., 2017). Other studies have shown that $S$. japonicum only develops in $O$. hupensis quadrasi at temperatures higher than $15.4^{\circ} \mathrm{C}$, with the fastest development occurring at $30.0^{\circ} \mathrm{C}$ (Yang et al., 2007; Zhou et al., 2009). A similar temperature range was reported in this study as well as in the study conducted in Davao del Norte (Belizario et al., 2017). Effective snail control strategies, as discussed earlier, may help mitigate the risk in low-land areas and in areas with suitable temperature range for the development of snail habitats with infected snails.

This study showed the usefulness of GIS technology in identifying and mapping possible high-risk areas for schistosomiasis. Through the generation of map layers, different schistosomiasis determinants could be visualized, and they proved to be helpful in identifying possible high-risk areas. This study considered the focal distribution of schistosomiasis by obtaining barangay-level data compared to the municipal-level data of the previous study in Davao del Norte (Belizario et al., 2017).

Application of other technologies in conjunction with GIS may improve the use of maps in surveillance. Remotely sensed data may be used to predict spread of schistosomiasis in nearby provinces by observing snail habitats in different ecologies (Seto et al., 2002). Spatio-temporal pattern analysis in GIS may also be used to investigate possible re-emergence or spread of schistosomiasis in areas where the infection has been eliminated or is not known to be endemic, respectively (Yang et al., 2013). Transmission models may be used to study the spatial spread of schistosomiasis, allowing prediction of future hotspots of the infection (Ciddio et al., 2016).

As seen in this study, also non-endemic barangays, such as Buntay, Iwayan and San Roque, have areas with favourable conditions for schistosomiasis transmission. Thus, these areas should be included in active surveillance to investigate possible spread of schistosomiasis (Kouadio et al., 2012). Efficient and sustainable program implementation may be possible through the use of GIS since the generated maps can be used by the LGU in Oras to develop an action plan to enhance the local implementation of the schistosomiasis control program by tailoring it to the needs of each barangay.

\section{Limitations of the study}

The study was limited by the unavailability of data on geographical location of irrigation canals from the concerned offices. Another limitation was the absence of updated data on temperature in Eastern Samar LGU. These limitations may be addressed through development of standard procedures in collecting and processing data for GIS. Data on snail colonies were also limited to areas routinely surveyed by the $\mathrm{DOH}$ and presence of snail colonies in other areas remains unknown. Improving the design of malacological surveillance is needed to help interrupt schistosomiasis transmission, which is defined as $0 \%$ incidence in human, snails and animals for 5 years (DOH, 2018). Malacological surveillance can be improved by adopting statistically valid procedures in identifying snail sites, training of personnel on malacological survey, and performing sentinel surveillance twice a year.

\section{Conclusions}

Efficient and sustainable program implementation is possible through the use of GIS. Generation of maps including areas with favourable conditions for schistosomiasis should lead to better prevalence surveys. Further improvements would follow by strengthening health education in areas where MDA and sanitary 
toilet coverage are low, implementing snail control in all areas with snail colonies, and focusing on the role of reservoir hosts in areas with high carabao population densities.

\section{References}

Belizario VY, delos Trinos JPCR, Silawan B, de Veyra CM, Hornido AB, Amoguis H, Basalo D, Dema-Ala C, Mantilla I, Layan R, 2017. The use of geographic information system as a tool for schistosomiasis surveillance in the province of Davao del Norte, the Philippines. Geospat Health 12:540.

Belizario VY, Molina VB, Miranda E, Ladia MA, Sison OT, Durano LP, Gerali PDR, Dejardin JTK, Lacuna JD, Cubarrubias DLP, 2018. War on worms and water, sanitation, and hygiene (WOW-A-WASH): integration of Helminthiasis control with water, sanitation, and hygiene in Haiyan-Stricken Areas in the Philippines. Technical Report.

Chen YY, Huang XB, Xiao Y, Jiang Y, Shan XW, Zhang J, Cai SX, Liu JB, 2015. Spatial analysis of Schistosomiasis in Hubei Province, China: a GIS-based analysis of Schistosomiasis from 2009 to 2013. PLoS One 10:e0118362.

Ciddio M, Mari L, Sokolow S, De Leo G, Casagrandi R, Gatto M, 2016. The spatial spread of schistosomiasis: A multidimensional network model applied to Saint-Louis region, Senegal. Adv Water Resour 108:406-15.

DOH, 2007. Administrative Order 2007-0015: Revised guidelines in the management and prevention of schistosomiasis.

DOH, 2009. Administrative Order 2009-0013: Declaring the month of July every year as the mass treatment and awareness month for schistosomiasis in the established endemic areas in the Philippinesitle.

DOH, 2010. Administrative Order 2010-0021: Sustainable sanitation as a national policy and a national priority program of the Department of Health.

DOH, 2016. Department Memorandum Order 2016-0212: Guidelines on the implementation of harmonized schedule and combined mass drug administration for the prevention and control of lymphatic Filariasis, Schistosomiasis, and soil-transmitted Helminthiasis.

DOH, 2018. Schistosomiasis control program. Available from: https://www.doh.gov.ph/schistosomiasis-control-program

DOH RO VIII, 2015. Malacological surveillance results summary.

DOH RO VIII, 2016. Schistosomiasis surveillance results and mass drug administration coverage summary.

Deardorff KV, Rubin Means A, Ásbjörnsdóttir KH, Walson J, 2018. Strategies to improve treatment coverage in communitybased public health programs: a systematic review of the literature. PLoS Neglect Trop Dis 12:e0006211.

Eastern Samar Provincial Health Office, 2016. LGU score card of Eastern Samar.

Gordon CA, Kurscheid J, Williams GM, Clements ACA, Li Y, Zhou X, Utzinger J, Mcmanus DP, Gray DJ, 2019. Asian schistosomiasis: current status and prospects for control leading to elimination. Trop Med Infect Dis 4:40.

Gray DJ, Williams GM, Li Y, Chen H, Forsyth SJ, Li RS, Barnett AG, Guo J, Ross AG, Feng Z, McManus DP, 2009. A clusterrandomised intervention trial against Schistosoma japonicum in the Peoples' Republic of China: bovine and human transmission. PLoS One 4:e5900.

Grimes JE, Croll D, Harrison WE, Utzinger J, Freeman MC,
Templeton MR, 2015. The roles of water, sanitation and hygiene in reducing schistosomiasis: a review. Parasite Vectors 8:1-16.

Higgs G, 2004. A literature review of the use of GIS-based measures of access to health care services. Health Serv Outcomes Res Methodol 5:119-39.

$\mathrm{Hu}$ Y, Li R, Bergquist R, Lynn H, Gao F, Wang Q, Zhang S, Sun L, Zhang Z, Jiang Q, 2015. Spatio-temporal transmission and environmental determinants of Schistosomiasis Japonica in Anhui Province, China. PLoS Negl Trop Dis 9:e0003470.

Karunamoorthi K, Almalki M, Ghailan K, 2018. Schistosomiasis: a neglected tropical disease of poverty: a call for intersectoral mitigation strategies for better health. J Health Res Rev 5:1-12.

Katanha A, Masocha V, 2014. Schistosomiasis an issue in flood prone area of DambakurimaWard 1, Muzarabani District of Zimbabwe.

Kerr K, 2004. Zoonoses: infectious diseases transmissible from animals to humans. J Clin Pathol 57:1120.

King C, 2010. Parasites and poverty: the case of Schistosomiasis. Acta Tropica 113:95-104.

King CH, Dickman K, Tisch DJ, 2005. Reassessment of the cost of chronic helmintic infection: a meta-analysis of disability-related outcomes in endemic schistosomiasis. Lancet 365:1561-9.

Kouadio IK, Aljunid S, Kamigaki T, Hammad K, Oshitani H, 2012. Infectious diseases following natural disasters: Prevention and control measures. Exp Rev Anti-Infect Ther 10:95-104.

Leonardo LR, Rivera PT, Crisostomo B, Sarol JN, Bantayan NC, Tiu WU, Bergquist NR, 2005. A study of the environmental determinants of malaria and schistosomiasis in the Philippines using Remote Sensing and Geographic Information Systems. Parassitologia 47:105-14.

McManus DP, Gray DJ, Li Y, Feng Z, Williams GM, Stewart D, Rey-Ladino J, Ross AG, 2010. Schistosomiasis in the People's Republic of China: The era of the three Gorges Dam. Clin Microbiol Rev 23:442-66.

MPDO (Oras Municipal Planning and Development Office), 2015. Topographic map and comprehensive land use in Oras, Eastern Samar.

NEDA (National Economic Development Authority), 2017. Philippine Development Plan 2017-2022. Available from: http://pdp.neda.gov.ph/wp-content/uploads/2017/01/PDP2017-2022-07-20-2017.pdf

Oras Rural Health Unit, 2016. Sanitary toilet coverage in Oras, Eastern Samar.

PAGRO (Eastern Samar Provincial Agricultural Office), 2016. Carabao population in Eastern Samar.

Peng WX, Tao B, Clements A, Jiang QL, Zhang ZJ, Zhou YB, Jiang QW, 2010. Identifying high-risk areas of schistosomiasis and associated risk factors in the Poyang Lake region, China. Parasitology 137:1099-107.

Philippine Statistics Authority, 2015. Region 8 Profile. Available from: http://www.nscb.gov.ph/activestats/psgc/regview. asp?region $=8$

PPDO (Eastern Samar Provincial Planning and Development Office), 2015. Topographic map and comprehensive land use in Eastern Samar.

Qin ZQ, Xu J, Feng T, Lv S, Qian YJ, Zhang LJ, Li YL, Lv C, Bergquist R, Li SZ, Zhou XN, 2018. Field evaluation of a loop-mediated isothermal amplification (LAMP) platform for the detection of Schistosoma japonicum infection in 
Oncomelania hupensis Snails. Trop Med Infect Dis 3:124.

Salazar MA, Law R, Pesigan A, Winkler V, 2017. Health consequences of Typhoon Haiyan in the Eastern Visayas Region using a syndromic surveillance database. PLoS Current Disasters doi:10.1371/currents.dis.4a3d3b4474847b2599aa 5 c5eefe $3 a 621$

Seto E, Xu B, Liang S, Gong P, Wu W, Davis G, Qiu D, Gu X, Spear R, 2002. The use of remote sensing for predictive modelling of Schistosomiasis in China. Photogram Engine Remote Sens 68:167-74.

United Nations Children's Fund, 2015. WASH pathway of change after Yolanda-one year on. Available from: https://www.communityledtotalsanitation.org/sites/communityledtotalsanitation.org/files/UNICEF_PhATS_Yolanda_One_year_on_0.pdf

van Dam GJ, Odermatt P, Acosta L, Bergquist R, de Dood CJ, Kornelis D, Muth S, Utzinger J, Corstjens PL, 2015. Evaluation of banked urine samples for the detection of circulating anodic and cathodic antigens in Schistosoma mekongi and S. japonicum infections: a proof-of-concept study. Acta Trop 141:198-203.

World Clim, 2000. Global climate data. Available from: https://www.worldclim.org/data/worldclim21.html

WHO, 2006. Preventive chemotherapy in human Helminthiasis: coordinated use of anthelminthic drugs in control interventions: a manual for health professionals and programme managers. World Health Organization, Geneva, Switzerland.

WHO, 2012. Schistosomiasis fact sheet. World Health Organization, Geneva, Switzerland.

WHO, 2017. Expert consultation to accelerate elimination of Asian Schistosomiasis. World Health Organization, Geneva, Switzerland. Available from: https://iris.wpro.who.int/bitstream/handle/10665.1/13938/RS-2017-GE-36-CHN-eng.pdf
WHO, 2020. Ending the neglect to attain sustainable development goals - a road map for neglected tropical diseases 2021-2030. World Health Organization, Geneva, Switzerland.

Wu XH, Zhang SQ, Xu XJ, Huang YX, Steinmann P, Utzinger J, Wang TP, Xu J, Zheng J, Zhou XN, 2008. Effect of floods on the transmission of schistosomiasis in the Yangtze River valley, People's Republic of China. Parasitol Int 57:271-6.

Yang GJ, Utzinger J, Sun LP, Hong QB, Vounatsou P, Tanner M, Zhou XN, 2007. Effect of temperature on the development of Schistosoma japonicum within Oncomelania hupensis, and hibernation of O. hupensis. Parasitol Res 100:695-700.

Yang K, Li W, Sun LP, Huang YX, Zhang JF, Wu F, Hang DR, Steinmann P, Liang YS, 2013. Spatio-temporal analysis to identify determinants of Oncomelania hupensis infection with Schistosoma japonicum in Jiangsu province, China. Parasites Vectors 6:138.

Zhang ZY, Xu DZ, Zhou XN, Zhou Y, Sun ZD, Zhang B, Gong ZL, Liu SJ, 2003. [Application of satellite image for surveillance of vegetation landscapes of Oncomelenia-snail habitats in marshland using unsupervised classification]. Zhonghua Liu Xing Bing Xue Za Zhi = Zhonghua Liuxingbingxue Zazhi 24:261-4 [In Chinese].

Zhou XN, Malone JB, Kristensen TK, Bergquist NR, 2001. Application of geographic information systems and remote sensing to schistosomiasis control in China. Acta Tropica 79:97-106.

Zhou X-N, Yang K, Yang G-J, Wu X-H, Kristensen TK, Bergquist R, Utzinger J, 2009. Potential impact of, and adaptation to, climate change influence on schistosomiasis transmission in China - a) experiences from China. IOP Conf Ser Earth Environ Sci 6:142002 